\title{
FREUD É MONISTA, DUALISTA OU PLURALISTA?*
}

Monah Winograd

Psicanalista, especialista em psicoterapia, pelo Ipub; doutora em Teoria Psicanalítica, pela UFRJ; pesquisadora da PUC-Rio/Faperj; autora do livro Genealogia do sujeito freudiano.

RESUMO: Este artigo trata de uma questão que surge sempre que a problemática do corpo na teoria freudiana é desdobrada. Seria Freud monista, dualista ou pluralista? Nosso primeiro esforço é definir estes termos do léxico filosófico, atentando para a sua generalidade. Em seguida, debruçamo-nos sobre a obra freudiana para mostrar que sua teoria não se encaixa nestas categorias, ou antes, ela aglomera os três termos já que trabalha simultaneamente com monismos, dualismos e pluralismos. Analisamos os conceitos de inconsciente, pulsão, equação etiológica e séries complementares para sustentar esta posição.

Palavras-chave: Monismo/dualismo, pluralismo, inconsciente, pulsão, etiologia.

ABSTRACT: Is Freud a monist, a dualist or a pluralist? This article deals with a question that always appears when we investigate the problem of the body in Freud's theory. Is Freud a monist, a dualist or a pluralist? Our first effort is to define these terms of the philosophical lexic, paying attention to its generality. Afterwards, we study the Freudian work in order to show that his theory does not fit into these categories. On the contrary, it puts together the three terms once it works at the same time with monisms, dualisms and pluralisms.

Keywords: Monism/dualism, pluralism, unconscious, trieb, etiology.

0 que queremos dizer quando falamos em 'problemática do corpo' na teoria freudiana? O termo 'problemática' refere-se a uma rede de problemas interligados, todos envolvendo a noção de corpo e suas articulações com noções vizinhas. Ba-

\footnotetext{
* Este trabalho faz parte de uma pesquisa em andamento no Departamento de Psicologia da PUC-Rio, com o apoio do programa de Fixação de Pesquisador da Faperj. No momento, estamos elaborando um inventário cronológico da temática do corpo na obra de Freud e, simultaneamente, investigando o encontro entre a teoria freudiana e as teorias cognitivas recentes.
} 
sicamente, podemos destacar os seguintes: 1) Qual a noção freudiana de corpo?; 2) Quais são seus elementos?; 3) Qual a relação entre corpo e aparato psíquico?

Quando começamos nossa investigação pelo terceiro problema, logo percebemos que não há ali uma diferença substancial entre corpo e psiquismo. Mais radicalmente, vemos o materialismo freudiano funcionar como uma base para a sua metapsicologia - raízes. Ao mesmo tempo, vemos Freud trabalhar com pares, mais complementares que opostos - galhos, ramos, primeiras bifurcações. Somos então tentados a classificar esta teoria como dualista. Pensando bem, ela também poderia ser enquadrada como pluralista por entender que a composição destes pares produz singularidades - folhas, flores e frutos. Daí a pergunta brotar quase de modo espontâneo: a teoria freudiana é um monismo, um dualismo ou um pluralismo?

Para uma primeira aproximação do problema, buscaremos definições que ajudem a entender a própria formulação do enunciado. As palavras 'monista', 'dualista' e 'pluralista' fazem parte do léxico filosófico e, antes de qualquer coisa mais, é preciso que nos ponhamos de acordo sobre os sentidos que elas fazem, mesmo não sendo nosso propósito um aprofundamento destas discussões no âmbito da filosofia, já que estamos investigando a metapsicologia freudiana. Nosso objetivo é apenas reunir as definições dos termos para deles extrair um sentido geral para cada um e, depois, verificar quais aspectos da obra freudiana induzem à classificação apressada desta teoria como monista, dualista ou pluralista.

Contudo, a própria tentativa de definir genericamente os termos nos leva a um impasse. Ou operamos na abstração lexical dos dicionários de filosofia (é o caso de consultar o velho Lalande) encontrando ali um grau de generalidade que satisfaz limitadamente; ou então mergulhamos no exame detalhado dos 'casos', isto é, dos sistemas conceituais ou de idéias que podem ser subsumidos a cada uma dessas noções, dando conta de que do ponto de vista dos sistemas conceituais só há singularidades que se repetem de maneiras diferentes. Assim, o dualismo cristão não é o mesmo de Descartes, o monismo de Spinoza não é o mesmo de Haeckel, etc.

Acreditamos que a questão sobre ser Freud monista, dualista ou pluralista ao invés de auxiliar na compreensão de seu sistema conceitual, atrapalha o entendimento, porque opera uma redução de sentido. A produção de Freud não deve ser subsumida a tais categorizações genéricas demais, pois ela tem como traço singular a impossibilidade de ser classificada satisfatoriamente em alguma destas categorias. Ele não é nem monista, nem dualista, nem pluralista. Quando muito, será monista, dualista e pluralista ao mesmo tempo. Afirmar apenas um destes aspectos é desconsiderar a complexidade desta construção teórica.

Temos o péssimo hábito de etiquetar as coisas e as idéias, acreditando assim melhor compreendê-las. Quando usamos termos terminados em ismo, estamos, 
na verdade, fazendo referência a um conjunto genérico e abstrato demais para nos ensinar alguma coisa realmente importante sobre nosso objeto de estudo, seja ele qual for. Afirmar que uma teoria é dualista, por exemplo, nos diz apenas que ela opera com dois. Mas que dois são estes, como se articulam, o que está em jogo na teoria, disto não ficamos sabendo. Por outro lado, às vezes, deixamos de ir adiante na investigação de algo quando ouvimos dizer que tal autor é monista, por exemplo. Ouvindo cantar o galo sem saber direito onde, acreditamos entender algo mais. Na verdade, entendemos menos, pois estes termos nada nos dizem sobre a especificidade de uma teoria, não nos ensinam sua geografia conceitual nem o sentido dos conceitos construídos e articulados.

Não etiquetemos também a teoria psicanalítica.

\section{O QUE É MONISMO? O QUE É DUALISMO? O QUE É PLURALISMO?}

1. Por "monista” indica-se todo sistema filosófico que considera o conjunto das coisas como redutível a uma unidade, seja do ponto de vista da substância, seja do ponto de vista das leis (lógicas ou físicas) pelas quais as coisas são regidas, seja do ponto de vista moral.

Do ponto de vista da substância, a palavra "monismo" se aplica às ontologias que remetem todas as coisas somente à matéria ou somente à alma. O monismo se divide, portanto, em monismo "materialista” (tudo pode ser reduzido à matéria) e monismo "idealista" (tudo pode ser reduzido à alma).

Do ponto de vista lógico e metafísico, “monismo” se refere ao sentido hegeliano do universo e a todos que apresentem o mesmo caráter, quer pela admissão da unidade do mundo, da existência do absoluto, da inteligibilidade essencial do ser, quer pela consideração do caráter apenas aparente e superficial da multiplicidade sensível, da individualidade e da duração. "Monismo" opõese, neste sentido, a "pluralismo", que vê no fundo das coisas a descontinuidade, a multiplicidade individual, a realidade do devir que altera os seres, a imprevisibilidade do futuro.

Do ponto de vista científico, filosófico e moral, “monismo” designa doutrinas como a de Haeckel, naturalista alemão que traduziu Darwin. Doutrina resumida por ele mesmo nos seguintes pontos, e oposta em cada um deles ao "dualismo":

“unidade do universo, sem antítese entre espírito e matéria; identidade de Deus e do mundo, que não foi criado, mas que evoluiu segundo leis eternas; negação de uma força vital independente das forças físicas e químicas; mortalidade da alma; rejeição da oposição estabelecida pelo cristianismo entre os fins da carne e os fins do espírito; excelência da natureza; racionalismo; religião da ciência, do bem e da beleza". (HAECKEL in LALANDE, 1968, p.357) 
Trocando em miúdos, a palavra “monismo” é usada para indicar toda doutrina ou sistema de pensamento que afirme certa unidade de explicação (redução a um só princípio, a uma só causa, a uma só tendência ou direção) para um domínio limitado de idéias ou de fatos (JACOB, 1990).

2. O termo "dualismo”, por sua vez, designa um tipo de raciocínio que admite a referência a uma dualidade de origem: duas substâncias irredutíveis uma à outra (Descartes) ou dois princípios últimos postos em exterioridade radical um relativamente ao outro. Mais especificamente, a palavra "dualismo" visa o sistema de pensamento que se desenvolve a partir de uma oposição primeira e originária.

Há ainda toda uma discussão ética derivada do fato de que a tomada de posição propriamente ontológica que se encontra na base das teorias dualistas se desdobra a partir de um julgamento de valor. Julgamento este que distribui os princípios em causa segundo um esquema de oposição e de exclusão, como por exemplo, entre ser e nada, luz e trevas, bem e mal. O maniqueísmo é uma das formas extremas deste sistema de pensamento, forma esta engendrada no seio da tradição cristã.

Contudo, o termo "dualismo" também pode ser e é amplamente usado apenas no sentido de "dualidade", como referência a uma relação de termos que se correspondem cada um com cada um.

3. Por fim, o termo "pluralismo" é utilizado de modo genérico para fazer referência às doutrinas e sistemas conceituais para as quais os seres que compõe o mundo são múltiplos, individuais, independentes e não devem ser considerados como simples modos ou fenômenos de uma realidade única e absoluta. Neste sentido lógico e metafísico, é o oposto de "monismo".

Mas, deve-se fazer uma distinção entre os pluralismos metafísico e epistemológico. No que concerne à metafísica, “pluralismo" se opõe a “monismo”, sendo o "dualismo" um caso particular do pluralismo. Há duas formas de pluralismo metafísico: a) uma mais flexível, cujo argumento é de que existe mais do que apenas uma coisa e b) outra mais rígida, que nega que estas coisas possam se reduzir a uma só. Nota-se que o pluralismo flexível é compatível com o monismo flexível, pois não nega a possibilidade de redução do múltiplo ao um. O materialismo, no sentido de que tudo o que existe é material, é um exemplo de monismo flexível (tudo tem a propriedade de ser material, de fazer parte do mesmo) e simultaneamente é um pluralismo flexível, pois aceita a pluralidade das coisas (existem muitas coisas materiais) (B. Russell e W. James).

O pluralismo epistemológico, por outro lado, sustenta que diferentes teorias podem ser adequadas e válidas. Isto pode se basear na visão de que existem a) diversas vias em direção a verdade, ou b) diversas formulações da verdade, ou c) que as diversas teorias concorrentes e eventualmente opostas trazem à luz diversos aspectos de uma mesma realidade. 


\section{FREUD É MONISTA OU DUALISTA?}

$\mathrm{Na}$ obra freudiana, podemos destacar algumas questões que, de acordo com o modo como são trabalhadas, podem induzir ao equívoco de classificar a teoria como um monismo ou um dualismo. Dependendo da ênfase dada, ela será dualista, monista ou os dois ao mesmo tempo, o que nos parece mais adequado. São elas:

O dualismo de princípios - será o princípio de realidade apenas um desdobramento do princípio de prazer? Tratar-se-á de apenas um princípio original do qual o outro 'brota' depois? Neste caso, não estamos diante de um caso de pensamento monista, já que originariamente o princípio regente do aparato psíquico seria apenas um? Ou, tratar-se-ia em verdade de dois princípios postos em relação de exterioridade, portanto de uma teoria dualista?

Na dualidade pulsional - há uma pulsão apenas ou duas ou inúmeras? De onde vem o adjetivo que determina a pulsão como sexual, autoconservativa, de vida ou de morte? Noutras palavras, seria Freud monista por supor que se trata de apenas uma pulsão a ser determinada como pulsão disto ou daquilo no instante de sua apreensão pelo aparato? Ou, ao contrário, seria Freud dualista, já que insiste fortemente em trabalhar com dualidades pulsionais que não podem ser reduzidas à unidade sob pena de fazer desaparecer o conflito, suporte da teoria?

Neste artigo, apenas teremos espaço para nos debruçarmos sobre o problema da qualidade pulsional, ou seja, de sua determinação como pulsão disso ou daquilo. O primeiro, infelizmente, fica apenas como indicação.

\section{AS DUALIDAdES PULSIONAIS}

No “Esboço de Psicanálise" (1938), Freud afirma que as pulsões são a causa última de toda a atividade, dando relevo ao sentido de princípio geral do vivo, força genérica, indeterminada e impessoal. Conforme a segunda classificação, as pulsões primordiais são duas, Eros (ou pulsão de vida) e pulsão de morte. Sua ação eficaz, conjunta ou contrária, "produz toda a variedade das manifestações da vida" (FREUD, 1938, p.147). Freud estabelece a analogia com a atração e a repulsão, as duas forças básicas da mecânica clássica, e cita Empédocles de Agrigento (495-435 a.C.).

A menção ao filósofo grego acontece com mais clareza num trabalho anterior, “Análise terminável e interminável” (1937). Ali, Freud se regozija por ter encontrado sua teoria da pulsão de morte num dos grandes pensadores da Antiguidade, Empédocles, que explicava as diferenças entre as coisas do mundo pela mescla entre quatro elementos: terra, água, fogo e ar. É certo que a teoria do grego era uma "fantasia cósmica”, enquanto a das pulsões pretende alcançar "validez biológica”. Mas, segundo Freud, essa diferença perde grande parte de seu valor em função de Empédocles considerar o universo tão animado quanto o ser vivo singular. Para o filósofo, a alma do mundo e a dos seres vivos era regida 
por dois princípios: o amor e a discórdia. E Freud cita um comentador dos présocráticos que acabara de ler: “(...) são forças naturais de eficiência pulsional, de modo algum umas inteligências conscientes dos fins” (CAPELLE, W., 1935 in FREUD, 1937, p.247).

Empédocles concebe o processo do mundo como uma alternância continuada de períodos nos quais o amor triunfa sobre a discórdia e vice-versa. O amor quer aglomerar tudo, mas, pouco a pouco a discórdia se insinua e desagrega. No processo de desagregação, nascem as coisas singulares e suas formas, frutos da luta entre as forças, até que se chega à dispersão total. E o ciclo recomeça por obra do amor, em sentido contrário. Freud encerra suas considerações sobre Empédocles dizendo que, se a pulsão de morte é o esforço para levar o vivo à condição de inerte, isso não significa necessariamente que uma pulsão análoga não tenha existido desde antes da aparição da vida.

Seja como for, observemos para onde caminhava o pensamento de Freud neste momento: ele beirava a afirmação de que haveria, na origem, apenas uma pulsão, entendida como força, um monismo pulsional, portanto. Mas, note-se que Freud apenas beirou esta afirmação, mantendo-se dentro dos limites que acreditava serem os seus. Ele trabalhava sobre o psiquismo humano e, dentro deste campo, o conceito de pulsão designava uma força capaz de expressão psíquica, gerada continuamente pelo corpo vivo. Quanto à natureza básica desta força, o metapsicólogo sempre sublinhou sua ignorância. Em 1920, por exemplo, declarou:

"O caráter impreciso de todas estas nossas elucidações a que chamamos metapsicológicas se deve, naturalmente, a nada sabermos sobre a natureza do processo excitatório nos elementos do sistema psíquico, e a não nos sentirmos autorizados a adotar uma hipótese a respeito dela. Assim, operamos continuamente com um grande X que transportamos para cada fórmula nova." (FREUD, 1920, p.30)

Mesmo não se sentindo autorizado a formular hipóteses sobre a natureza do processo excitatório no sistema psíquico, Freud tinha algumas suspeitas que ele não escondia. Acreditava, por exemplo, que processos químicos estavam na base somática das pulsões sexuais, embora não estivesse em condições de indicar em que estes processos se diferenciam dos não sexuais e qual a sua natureza. Em 1905, nos “Três ensaios de teoria sexual”, apresentou sua hipótese:

“Outra hipótese provisória na doutrina das pulsões, que não podemos omitir aqui, reza o seguinte: os órgãos do corpo oferecem excitações de duas classes, baseadas em diferenças de natureza química. A uma destas classes de excitação designamos como a especificamente sexual, e ao órgão afetado, como a 'zona erógena' da pulsão parcial sexual que parte dele.” (FREUD, 1905, p.153. Grifo nosso) 
Excitações de duas classes na “origem fisiológica” das pulsões? Como conjugar esta idéia com a de que a pulsão é a causa última de toda atividade? Simplificadamente, o que determina se uma pulsão é de um tipo ou de outro? Ou antes, uma pulsão é de um tipo ou de outro em sua natureza? De modo contrário ao que afirmara antes, Freud ensaia outra resposta: “(...) todas as pulsões são qualitativamente da mesma índole, e devem seu efeito somente às magnitudes de excitação que conduzem ou, quiçá, ainda a certas funções desta quantidade" (FREUD, 1915, p.119).

O problema é enunciado em várias ocasiões, mas nunca resolvido. Ele já estava lá desde o começo, desde 1895 pelo menos. No “Projeto”, Freud tentou resolvêlo pela idéia de "período”, segundo a qual as qualidades percebidas na consciência viriam pela variação no ritmo e na freqüência das quantidades recebidas pelo aparato psíquico e, internamente, em trânsito. A pulsão é uma destas quantidades recebidas - mais especificamente a que engendra o sistema e o alimenta por dentro. Nesse sentido, é bem mais do que uma noção psicológica apenas: é uma noção ontológica, pois se refere à própria natureza do psíquico.

Luiz Alfredo Garcia-Roza (1986) sugere que entendamos a pulsão como pura potência, dispersa e indeterminada. A determinação para o indeterminado das pulsões viria, não de sua fonte corporal (o corpo pulsional), mas do aparato psíquico que, ao capturá-la, lhe dá uma direção. Assim, por exemplo, o sexual seria a forma ou a determinação que uma pulsão recebe, não o seu atributo. O mesmo vale para cada pulsão parcial: dizer que uma pulsão é escópica, oral, anal, e por aí vai, é indicar a variedade das fontes pulsionais e não fixar uma diferença qualitativa entre elas. Em si mesma, toda pulsão é uma potência dispersa sem determinação intrínseca. A determinação é dada na apreensão, ou se preferirmos, na inscrição desta força no psiquismo.

Mas, se é assim, o dualismo pulsional tão caro a Freud deixaria de fazer sentido, pois, em última instância, haveria apenas a pulsão. Garcia-Roza resolve este problema propondo que o dualismo seja pensado como um dualismo de modos da pulsão, não de natureza. As diferenças qualitativas entre as pulsões viriam de seus modos de presentificação no psiquismo e não de uma diferença ontológica entre elas. De um lado, o aparato psíquico que ordena e organiza, de outro, o caos pulsional. Mas, isso não significa que as pulsões sejam todas iguais. Sabemos que elas produzem efeitos os mais diversos, tanto num mesmo indivíduo, quanto de um indivíduo para outro. Efeitos que se devem não apenas à rede de fantasias que a pulsão alimenta e na qual ela se inscreve, mas também a uma variação quantitativa nas e das próprias pulsões, ou, nas palavras de Freud, “às magnitudes de excitação que conduzem”.

É certo que a qualidade pulsional vem de sua inscrição no aparato anímico, como também é certo que as pulsões variam quantitativamente e que esta varia- 
ção produz efeitos diferenciados. Não devemos esquecer de que se trata de um dos conceitos fronteiriços entre o anímico e o somático. Do mesmo modo, também não devemos esquecer que a pulsão é o conceito-limite por excelência, a causa última de toda atividade, inclusive a metapsicológica. Sendo a causa última de toda a atividade, para além da pulsão não haveria mais conceitos psicanalíticos.

Monismo pulsional e dualismo pulsional: ambas as expressões são corretas. De um lado, devemos dizer que Freud é dualista por trabalhar com dualidades (pulsão de autoconservação / pulsão sexual e pulsão de vida / pulsão de morte) supostas desde a origem do aparato psíquico. Por outro lado, também devemos afirmar que Freud é monista na medida que considera que a determinação das pulsões deriva de seu modo de presentificação no psiquismo. Substancialmente, haveria apenas uma pulsão, e não duas: pulsão de vida e pulsão de morte não seriam duas substâncias distintas, como são a alma e o corpo cartesianos. Em Freud, o conceito de pulsão é único, apenas uma substância-pulsão cuja adjetivação/inscrição psíquica como de autoconservação, sexual, de vida ou de morte varia.

Ou seja, de acordo com a ênfase num ou noutro aspecto, nossa categorização desliza de um lado para outro, pois o certo é ser Freud monista e dualista ao mesmo tempo.

\title{
FREUD É PLURALISTA?
}

Se evidenciarmos alguns outros pontos da obra freudiana, entenderemos por que acontece de ela ser considerada como expressão de um modo de pensar pluralista. Por exemplo, em 1917, Freud escreve:

\begin{abstract}
“A mim me parece tão audacioso dar uma alma à natureza quanto desespiritualizá-la radicalmente. Deixemo-lhe, portanto, a sua grandiosa multiplicidade que se eleva do inanimado ao animado orgânico, do vivo corporal ao espiritual. O ics constitui certamente o intermediário correto entre o corporal e o espiritual, talvez o missing link buscado há tanto tempo. Mas, porque afinal percebemos isso não devemos perceber nenhuma outra coisa mais? Receio que o senhor. seja também um filósofo e que tenha a tendência monística a desdenhar todas as belas diferenças em troca do engodo da unidade. Estaremos assim nos livrando das diferenças?” (FREUD, 1917 in GRODDECK, 1994)
\end{abstract}

Com estas palavras Freud respondia à carta de apresentação que George Groddeck tinha lhe escrito. Se Groddeck defendia a unidade das coisas num Isso pré-individual, eterno e infinito (LEWINTER, 1969), Freud apontava para as diferenças e para a multiplicidade. Em pelo menos mais dois outros momentos de sua teorização pode-se notar claramente a presença destas idéias. 
O primeiro é o conceito de sistema inconsciente e o segundo são as noções de equação etiológica e séries complementares, primas da idéia de sobredeterminação. O primeiro (sistema inconsciente) evidencia um modo de pensar pluralista em sentido epistemológico, pois destaca que a verdade pode ser formulada de diversos modos. Melhor dizendo, o conceito de sistema inconsciente não permite considerar a verdade, somente verdades sempre parciais e prontas a rearranjos. O segundo momento (equação etiológica e séries complementares) da teoria freudiana é, na verdade, menos um instante e mais uma problemática que permeia a obra toda. Diz respeito à questão da etiologia psíquica, ao quanto Freud levava em conta a pluralidade de causas nos processos de subjetivação.

\section{O INCONSCIENTE COMO MULTIPLICIDADE VIRTUAL}

O inconsciente freudiano não é o misterioso nem o caótico, não é algo que está abaixo da consciência, nem tem profundidade. "Inconsciente" é o nome dado a um sistema psíquico organizado que, juntamente com outro sistema, o préconsciente/consciente, forma o aparato psíquico humano. Cada sistema é um lugar psíquico virtual não localizável, evidentemente, em elementos orgânicos do sistema nervoso. Para explicar estes lugares virtuais, Freud faz uso da metáfora do telescópio, segundo a qual os sistemas psíquicos seriam o "entre" as lentes do telescópio e as representações que os compõem seriam as imagens que se formam pela passagem dos raios de luz (FREUD, 1900).

Como qualquer sistema, o inconsciente apresenta características próprias. Uma delas é a ausência do símbolo da negação. Outra é a possibilidade de haver diferenças de quantidade de investimento numa ou noutra representação ou grupo de representações - sem que haja exclusão por incompatibilidade. Ainda outra característica é a grande mobilidade dos investimentos (energia livre) que circulam no sistema. Devemos ainda dizer que o inconsciente é atemporal, pois os processos que ali ocorrem não sofrem a ação do tempo: seu tempo é sempre o presente, sendo o passado uma construção operada pelas reorganizações dos traços de memória que formam as representações.

Para Freud, desde o abandono da teoria do trauma em 1897, o sentido do que acontece a um sujeito deriva, não do acontecimento em si, mas das articulações atuais entre as representações que o sujeito faz, sempre prontas a novos rearranjos e novas significações. O tempo do psiquismo não é linear e seqüencial, é lógico. O conceito de inconsciente leva ao entendimento da história (individual ou coletiva) como uma construção que além de não ser definitiva, é determinante apenas na medida que é (re)feita na atualidade. O presente constitui o passado e abre o futuro como possibilidade de diferença.

Criação e movimento, produção de diferença e construção incessante de si, não se deve definir o inconsciente como o lugar da origem, do sentido oculto 
que determina o sujeito. O sistema inconsciente aponta, antes de tudo, para uma multiplicidade virtual de significações possíveis. ${ }^{1}$ Vejamos por quê.

A definição mais geral de sistema é: conjunto de elementos relacionados entre si funcionalmente, de modo que cada elemento do sistema é função de algum outro elemento, não havendo nenhum elemento isolado. Esta definição nos indica não se tratar, no caso do sistema inconsciente, de um continente composto de conteúdos que é preciso revelar. O conceito de sistema refere-se a um todo organizado, a um conjunto de elementos relacionados entre si segundo determinadas leis - uma rede, para usar termos mais atuais. Vimos rapidamente como ocorrem rearranjos nesta rede e como o passado e o futuro jorram do presente, explodindo a determinação de um tempo linear e cronológico. O inconsciente se apresenta nesta multiplicidade virtual de significações atualizada em cada uma de suas formações. Não é ele que, de antemão, determina estas formações. O inconsciente está na multiplicidade de sentidos atualizada em cada ponto do discurso consciente no qual um não-sentido se produz. Produção de não-sentido da qual o próprio estatuto da representação em Freud dá conta.

O que o metapsicólogo entende por representação não é, como em Descartes por exemplo, o objeto representado. Já no texto sobre as afasias (1891), Freud fala de representações, utilizando, mais especificamente, os termos representação-objeto e representação-palavra, não representação de objeto ou de palavra. ${ }^{2}$ Para Freud, a questão não era a da representação verdadeira do mundo e das coisas, pois o sentido de uma representação não seria dado pelo referente externo que, no caso da palavra, ela designaria.

No texto de Freud supracitado, a palavra foi definida como uma representação complexa cujos elementos (acústicos, visuais e cinestésicos) devem estar associados entre si. Estes elementos são as imagens mnêmicas, inscrições de impressões que se associam entre si e que darão origem às representações. Mas, o que dá à palavra seu sentido? De onde vem seu significado? A resposta é simples: “(...) a palavra adquire a sua denotação pela ligação com a representação-objeto, pelo menos se nos limitarmos à consideração dos substantivos" (FREUD, 1891, p.70). Mas, também a representação-objeto é definida como um complexo, que só receberá sua unidade pela associação com a representação-palavra. Ou seja, o objeto não é a imagem da coisa ou de algum referente externo ao aparato. O mundo nos oferece apenas uma diversidade sensível, percebida e armazenada sob a forma de

\footnotetext{
${ }^{1}$ Empregamos o termo 'virtual' para designar o que é em potência por oposição ao que é em ato. Neste sentido, o virtual não pode ser identificado ao resultado de sua atualização, pois a atualização do virtual deve ser entendida como criação. O virtual seria como um complexo problemático que chama a invenção de um processo de resolução - a atualização (LEVY, 1995). ${ }^{2} \mathrm{O}$ que aqui denominamos de representação-objeto receberá o título de representação-coisa no artigo O inconsciente, de 1915. E o que, em 1915, Freud chama de representação-objeto refere-se à associação entre representação-coisa e representação-palavra.
} 
traços, que se associam formando as representações-palavra e as associações de objeto. Estas associações de objeto se tornarão representação-objeto pela articulação com a palavra. Somente assim, o objeto adquire unidade e identidade.

Nota-se que, tanto o significado da palavra quanto a identidade do próprio objeto decorrem da associação entre representações. Portanto, o que podemos chamar de efeito de significação não provém da coisa, mas das relações entre as representações: a representação-palavra adquire sentido na relação com a representação-objeto que, por sua vez, se organiza como tal nesta mesma relação. Daí falarmos em representação-palavra e representação-objeto, e não em representação de palavra ou de objeto.

Aqui, estamos próximos da noção de signo lingüístico em Saussure (1961) e, conseqüentemente, da apropriação que Lacan (1953 e 1957) faz disto. Para Saussure, o signo não é a união de uma palavra a uma coisa, mas a ligação entre uma imagem acústica (o significante) e um conceito (o significado). Este último define-se como a "representação psíquica” da coisa, só adquirindo sentido através do processo de significação. Assim, a significação não é a priori, não é anterior ao objeto ou à palavra. O que equivale a afirmar que as representações não recebem seu sentido das coisas, mas sim das relações que estabelecem entre si. Podemos dizer que a relação entre associações de objeto e palavras produz um efeito de significação e, portanto, caracteriza-se como uma relação significante.

Apoiando-se nesta teoria saussuriana do signo, Lacan apresenta sua leitura do inconsciente. Como vimos, Saussure define o signo a partir de seu caráter arbitrário: o elo entre significante e significado não é natural, pois nada há num que determine sua ligação ao outro. Isso não significa que os falantes possam unir significantes a significados como quiserem; apenas, a relação entre eles não apresenta laços naturais, levando-nos a concluir que não há anterioridade de um em relação ao outro, são termos contemporâneos. Porém, embora façamos referência a um signo, ele não é uma entidade isolada; ao contrário, o signo só pode ser pensado a partir de sua relação a outros signos. Nesta relação, ele adquire o seu valor: um signo só existe em função e na relação com outros signos, a partir da qual eles significam.

Nesta rede de signos, cada elemento é definido diferencialmente por uma relação de oposição aos demais, relação na qual o significado será determinado. Noutras palavras, a significação, mais do que o ato que une os dois termos componentes do signo, como queria Saussure, aparece como efeito de articulação. Assim, podemos definir o inconsciente como uma cadeia formada de elementos distintos e diferenciais, as representações, as idéias ou os signos. ${ }^{3}$

\footnotetext{
${ }^{3}$ Embora haja todo um debate sobre a equivalência dos termos 'representação', 'signo' e 'idéia', usamos os três de modo intercambiável, ressaltando sua proximidade semântica.
} 
Sabemos que o inconsciente obedece aos mecanismos de condensação e deslocamento. No primeiro, os signos estão sobrepostos uns aos outros, como na metáfora. No segundo, há uma substituição de um signo por outro, como na metonímia. Destas duas figuras, a metáfora pode ser destacada como o mecanismo que põe o pensamento inconsciente em movimento. A metonímia aparece sobre um fundo de significado já constituído: é o discurso coerente ou coerência metonímica. Refere-se a uma linguagem cujo objetivo é dar conta da clareza de raciocínio, da exigência de coerência.

Vimos, contudo, que qualquer articulação entre signos implica a multiplicidade de sentidos possíveis, o que, por si só, rompe com a ordem metonímica. É o símbolo metafórico que apresenta esta característica de suportar uma variação infinita de sentidos, porque a metáfora supõe a existência de uma cadeia inconsciente de signos, que duplica a do enunciado. Uma substituição se produz resultando num non-sense, num não-sentido, que, por sua vez, exige a emergência de novos sentidos, irredutíveis à cadeia metonímica. Assim, este nãosentido é o ponto fundamental, pois ao quebrar a cadeia metonímica, ele atualiza e movimenta a multiplicidade de sentidos possíveis (ROSOLATO, 1988). Tais quebras são as formações do inconsciente, que abrem a possibilidade de produção de novas articulações significantes, pondo a cadeia em movimento. São os pontos do discurso consciente nos quais uma segunda estrutura se insinua, abrindo a possibilidade de pensar diferentemente, de produzir o novo, criando a si mesmo (LEMAIRE, 1989). Esta segunda estrutura não traz sentidos já prontos, dos quais é preciso tomar consciência. Ao contrário, o que assim se descobre é a possibilidade que o sujeito tem de se servir desta segunda estrutura para significar algo totalmente diferente do que ela diz. É esta diferença que define o sujeito do inconsciente, sempre distinto de si mesmo, pois ele é o próprio ato de produção.

Com isso, verificamos que o conceito de inconsciente implica a suposição de que não há uma verdade única, originária ou mesmo oculta. Ao contrário, pensar em termos de rede produtora de sentido é entender, por um lado, que existem várias vias de acesso à verdade e, por outro, que existem várias verdades.

\section{A PLURALIDADE DAS CAUSAS: A EQUAÇÃO ETIOLÓGICA E AS SÉRIES COMPLEMENTARES}

O outro exemplo que poderia ilustrar, por assim dizer, o aspecto "pluralista" do pensamento freudiano são as noções de equação etiológica e de séries complementares, parentes diretas da idéia de sobredeterminação. Nestas idéias está presente a suposição de que, pelo menos no que se refere ao psiquismo, nenhuma causalidade é simples. Trata-se sempre de uma equação na qual uma pluralidade de fatores entram em jogo numa relação de variação quantitativa. 
Em 1895, Freud introduziu uma expressão que o acompanhou dali em diante: equação etiológica. A idéia que ela expressava era a de que na causação das neuroses em particular e da vida psíquica em geral vários tipos de causas interagem numa relação quantitativa. São elas:

Condição: fatores em cuja ausência o efeito nunca se produz, mas que são incapazes de gerá-lo por si mesmos, pois falta a causa específica. São, por exemplo, os fatores hereditários, fatores cuja alteração é dificílima;

Causa específica: fatores presentes em todos os casos em que o efeito se dá. Quando presentes na quantidade ou intensidade requerida bastam para produzir o efeito, desde que as condições também sejam cumpridas. Também são causa necessária, mas sua entrada em ação é mais recente, o que os torna mais suscetíveis a alterações;

Causas concorrentes ou auxiliares: fatores que não estão necessariamente presentes todas as vezes, nem podem, qualquer que seja a sua escala de ação, produzir o efeito por si mesmos, mas que operam em conjunto com as condições e a causa específica para satisfazer a equação etiológica. São quaisquer perturbações "banais" como emoção intensa, susto, esgotamento físico etc.;

Causa precipitante ou desencadeante: a que aparece por último na equação, precedendo imediatamente a aparição do efeito. Sua natureza essencial é apenas esse fator temporal.

Dentre estas classes de causas, apenas duas são necessárias, a condição e a causa específica. O fato de serem ambas necessárias não significa que tenham a mesma natureza ou que operem da mesma maneira. Muito pelo contrário. Freud identificava, no efeito produzido, as manifestações de uma e de outra. Completou o quadro acima com as seguintes especificações sobre as relações recíprocas entre os diferentes fatores etiológicos:

- Se ocorrerá ou não uma afecção neurótica, depende de um fator quantitativo, qual seja, a carga total sobre o sistema anímico ("sistema nervoso", na época destas formulações) em proporção à sua capacidade de resistência. Tudo o que possa manter ou retrair este fator abaixo de certo limite possui eficácia terapêutica, pois faz com que a equação etiológica não se cumpra. Por outro lado, condição e causas específicas (as únicas necessárias) podem substituir-se uma à outra no que tange à quantidade, ou seja, o mesmo efeito acontece quando a etiologia específica é muito grave e a condição é moderada, ou o contrário;

- A dimensão ou o alcance de uma neurose depende, em primeira instância, da extensão da "carga hereditária”. Ou seja, a hereditariedade funciona como um multiplicador introduzido num circuito elétrico, aumentando muitas vezes o desvio da agulha;

- A forma que a neurose assumirá - a direção do desvio da agulha do circuito elétrico - é determinada exclusivamente pelo fator etiológico específico. 
A primeira especificação (o fator quantitativo) trazia em si a necessidade de Freud afirmar o método de tratamento que tinha inventado e que incidia sobre as causas específicas, mais suscetíveis a alterações do que os fatores hereditários porque mais recentes. Se hoje em dia, com todo o desenvolvimento tecnológico que permitiu à biologia expandir-se, qualquer intervenção nestes fatores hereditários já é complicada sob diversos aspectos, na juventude de Freud, ela era quase inimaginável.

A segunda e a terceira afirmações diferenciam as manifestações da hereditariedade e da causa específica no efeito produzido. A primeira é condição, como uma quantidade já dada que multiplica o efeito da causa específica, sendo que uma pode substituir a outra neste aspecto quantitativo. A segunda, a causa específica, influi na escolha da neurose, ou seja, no tipo de afecção ocorrida, no porquê desta e não de outra. Portanto, são dois problemas interconectados que Freud pretendia resolver: o da origem da neurose em geral e de cada neurose em particular. Embora um implique necessariamente o outro, são problemas diferentes. O primeiro pode ser alargado para a questão da própria constituição do psiquismo: o que importa na formação de um psiquismo, o pedigree do indivíduo ou o que foi adquirido mais recentemente?

Em 1916, a equação etiológica ganha uma complementação. Na $22^{\text {a }}$ das conferências introdutórias proferidas nos EUA, aparece pela primeira vez a noção de séries complementares. A essa altura, a idéia de que os seres humanos contraem uma neurose quando lhes é retirada a possibilidade de satisfazer sua libido - em outras palavras, por uma frustração - não era nova para o metapsicólogo e seus colaboradores. Em todos os casos de neurose, a frustração da satisfação da libido estava presente, o que fazia dela uma causa específica na equação etiológica. Mas, como vimos, a causa específica só é capaz de produzir neurose se as condições estiverem cumpridas - causa específica e condição operam em conjunto numa relação quantitativa. Ou seja, apenas a frustração não basta; é preciso considerar também a peculiaridade de quem ela afeta.

Para Freud, é preciso que certa constituição e certas exigências “nocivas” da vida estejam presentes para que uma neurose ocorra, o que pode acontecer em quantidades variadas caso a caso, quando um aumenta, o outro diminui, seguindo o princípio da equação etiológica. Pode-se até ordenar os casos de contração de neurose numa série na qual, numa das extremidades se encontrariam aqueles nos quais se pode dizer com segurança que, em conseqüência de seu desenvolvimento libidinal, os sujeitos teriam neurotizado de qualquer maneira em quaisquer circunstâncias. Na outra extremidade, estariam aqueles outros que, inversamente, teriam escapado da neurose se a vida não lhes tivesse jogado nesta ou outra situação. Entre os dois extremos, os casos nos quais “(...) um mais ou um menos de constituição sexual predisponente se conjuga com um mais ou um 
menos de exigências daninhas da vida" (FREUD, 1916-17, p.316). Noutras palavras, casos nos quais a constituição sexual não teria provocado a neurose se não houvesse tais exigências da vida, e estas não teriam tido o efeito que tiveram com outra situação da libido. Às séries como esta, Freud propôs o nome de 'séries complementares', nas quais os fatores em questão se conjugam, cada equação etiológica produzindo um efeito diverso de acordo com a intensidade da frustração e com a rigidez das fixações libidinais.

Porém, para Freud, na etiologia das neuroses havia mais em jogo do que apenas uma frustração externa acidental somada a uma situação libidinal. O exemplo usado pelo metapsicólogo para ilustrar sua teoria foram os casos nos quais indivíduos até então sãos neurotizavam de repente, sem que a vida tivesse lhes feito exigências maiores do que as usuais. Em tais casos, poder-se-ia facilmente identificar a ocorrência de um conflito psíquico: “Um fragmento da personalidade sustenta certos desejos, outro se revolta e se defende deles" (FREUD, 191617, p.318). Sem um conflito deste tipo, não há neurose. Mas, assim como ocorre com a frustração, nem todo conflito produz neurose: nossa vida anímica é agitada o tempo todo por conflitos com os quais temos que lidar. Para que um conflito se torne patogênico, é preciso que certas condições se cumpram. Nos casos em que a natureza e a intensidade da frustração são fatores notáveis, o conflito é engendrado a partir da exigência de que a libido busque outros objetos e caminhos para sua satisfação. A condição do conflito é que estes outros objetos despertem desaprovação por uma parte do psiquismo, de modo que se produza um veto que impossibilite a nova modalidade de satisfação. Não obstante, as aspirações libidinosas vetadas conseguem impor-se fazendo certos rodeios, sendo obrigadas a driblar o veto através de certas desfigurações e atenuações. Os rodeios são os caminhos da formação de sintomas e os sintomas são a satisfação nova ou substitutiva que se fez necessária pela frustração. Em poucas palavras, para que uma "frustração exterior" tenha efeitos patogênicos, é preciso que se some a uma "frustração interior". A primeira elimina uma possibilidade de satisfação, a segunda pretende excluir outra em torno da qual explode depois o conflito.

Nesta época de sua obra, Freud pensava o conflito psíquico como o resultado do confronto entre forças pulsionais sexuais e forças pulsionais do eu, entre a sexualidade e o eu. Conflitos que, é bom lembrar, não são, para Freud, privilégio dos neuróticos. Todos enfrentam a mesma luta para domesticar suas pulsões, de modo que, entre as condições da saúde e da doença não há nenhum tipo de diferença qualitativa. Um acréscimo na quantidade de libido na economia psíquica, "por ter-se alcançado certa trama da vida e por causa de processos biológicos que obedecem a uma lei (...)” (FREUD, 1912, p.241), pode muito bem romper o equilíbrio da saúde e estabelecer o conflito, condição para uma neurose. Do mesmo modo, a debilitação do eu por doença orgânica ou por uma de- 
manda particular de sua energia pode fazer sair à luz neuroses que, de outro modo, teriam permanecido latentes, apesar da predisposição existente. De novo, trata-se de variações de quantidade, do quanto de libido cada eu singular é capaz de aplicar, dominar ou manter em tensão em cada período de sua existência. Todos os outros fatores externos e internos - frustração, fixação - permanecem ineficientes se não atingirem certa medida de libido e não provocarem uma estase libidinal de certa monta, a partir da qual o eu não pode mais se defender sem danos.

Ambos, sexualidade e eu, passariam por fases ou estágios de desenvolvimento paralelos e interconexos durante os quais se organizariam. Destes desenvolvimentos dependem tanto a resistência do eu, quanto a rigidez das fixações libidinais. Estes dois fatores constituem o que Freud chamou, do ponto de vista da ocorrência da neurose, de predisposição.

O esquema da equação etiológica da época da teoria do trauma (até 1897) era o seguinte:

constituição hereditária + experiências infantis traumáticas e/ou experiências atuais = neurose

Agora, com a complexificação da idéia de predisposição, o esquema ganhou mais um nível: ${ }^{4}$

NÍVEL 1

(Constituição + experiências infantis $=$ fixação da libido $)+$ capacidade de resistência do eu $=$ predisposição

NÍVEL 2

predisposição + experiências acidentais do adulto (traumas) $=$ neurose

A predisposição seria o resultado da conjugação entre o herdado - hoje em dia, costumamos dizer "o genético" - e o adquirido pela experiência na trajetória de vida. Os dois formam outra série complementar parecida com a que foi proposta entre predisposição e experiências acidentais do adulto. Em ambas as séries, podem-se encontrar os mesmos casos extremos e as mesmas relações de substituição conforme o princípio da equação etiológica. Noutras palavras, os fatores em jogo na etiologia das neuroses e nos processos de subjetivação em geral são incontáveis, plurais. Pode-se, quando muito, identificar um ou outro mais intenso, mais visível, mas jamais reduzir a equação a apenas um de seus termos.

\footnotetext{
${ }^{4}$ Este esquema baseia-se no que Freud desenhou na $23^{\mathrm{a}}$ conferência de introdução à psicanálise (1916-17). No esquema de Freud, a constituição aparece especificada como constituição sexual e a predisposição não inclui explicitamente a capacidade de resistência do eu.
} 
Tendo percorrido estes recantos da teoria freudiana, podemos finalmente perceber que qualquer enquadramento da obra é sempre um recorte, uma ênfase dada pela leitura. Precisamos tomar o cuidado em não nublar as questões importantes categorizando, como costuma acontecer ao fazermos uso de termos terminados em ismo, como monismo, dualismo, pluralismo. Freud só será monista, dualista ou pluralista se extirparmos parte de sua obra. Na verdade, a própria pergunta sobre o ismo no qual a obra freudiana se encaixa é um falso problema. Não é isso o que é realmente importante. A própria tentativa de categorizar, e até mesmo a preocupação em fazê-lo, impede que se perceba a singularidade da obra freudiana. Afirmar categoricamente que se trata de uma doutrina monista, dualista ou pluralista é roubar a força das idéias freudianas, deixar de entender seus conceitos e de ver seu alcance.

Recebido em 9/2/2004. Aprovado em 19/3/2004.

\section{REFERÊNCIASS}

FREUD, S. (1891/1977) A interpretação das afasias. Lisboa: Edições 70. 1976.

(1976) Obras completas de Sigmund Freud. Buenos Aires: Amorrortu.

(1895) “A propósito de las criticas a la 'neurosis de angustia”,, v. 3, p. $117-138$.

(1900) “La interpretación de los sueños", v. 5, p. 345-706.

(1905) “Tres ensayos de teoría sexual”, v. 7, p. 109-222.

(1912). "Sobre los tipos de contracción de neurosis”, v. 12, p.233246.

(1915a). "El inconciente”, v. 14. p.153-201.

(1915b). “Pulsiones y destinos de pulsión”, v. 14, p.105-134.

(1916-17a). "22 a Conferencia: Algunas perspectivas sobre el desarrollo y la regresión”, v. 16, p. 309-325.

(1916-17b). "23 a Conferencia: Los caminos de la formación de síntoma”, v. 16, p.326-343.

(1920) “Más allá del principio de placer”, v. 18, p. 1-62.

(1937) “Análisis terminable e interminable”, v. 23, p.211-254.

(1940 [1938]) “Esquema del psicoanálisis”, v. 23, p.133-210.

GARCIA-ROZA, L. A. (1986) Acaso e repetição em psicanálise. Rio de Janeiro:

Zahar.

GRODDECK, G. (1970/1994) O homem e seu isso. São Paulo: Perspectiva.

JACOB, A. (dir.) (1990) Encyclopédie philosophique universelle. Paris: PUF.

LACAN, J. (1953/1966). "Fonction et champ de la parole et du langage", in Écrits. Paris: Seuil.

(1957/1966) "L’instance de la lettre dans l'inconscient ou la raison depuis Freud”. 
LALANDE, A. (1968) Vocabulaire technique et critique de la philosophie. Paris: PUF.

LEMAIRE, A. (1989) Jacques Lacan, uma introdução. Rio de Janeiro: Campus.

LEVY, P. (1995) Qu'est-ce que le virtuel? Paris: Éditions la Découverte.

LEWINTER, R. (1969) Préface, in GRODDECK, G. (1969). La maladie, l'art et le symbole. Paris: Gallimard.

ROSOLATO, G. (1988). Elementos de interpretação. São Paulo: Escuta.

SAUSSURE, F. (1961) Curso de lingǘstica geral. São Paulo: Cultrix.

WINOGRAD, M. (1998) Genealogia do sujeito freudiano. Porto Alegre: Artes Médicas.

Monah Winograd

Rua Prof. Luiz Cantanhede 130/302

Laranjeiras 22245-040 Rio de Janeiro RJ

winograd@uol.com.br 